\title{
Evaluation and directed evolution for thermostability improvement of a GH 13 thermostable a-glucosidase from Thermus thermophilus TC11
}

Cheng Zhou ${ }^{1,2}$, Yanfen Xue ${ }^{1,2}$ and Yanhe $\mathrm{Ma}^{1,2^{*}}$

\begin{abstract}
Background: Thermal stable a-glucosidases with transglycosylation activity could be applied to the industrial production of oligosaccharides as well as conjugation of sugars to biologically useful materials. Therefore, a-glucosidases isolated from thermophiles have gained attention over the past decade. In this study, the characterization of a highly thermostable a-glucosidase and its thermostability improved mutant from newly isolated strain Thermus thermophilus TC11 were investigated.

Results: The recombinant a-glucosidase (TtAG) from Thermus thermophilus TC11 was expressed in Escherichia coli BL21 (DE3) and purified. The purified enzyme had a molecular mass of $184 \mathrm{kDa}$ and consisted of 59-kDa subunits; it showed hydrolytic activity for pNP-a-D-glucopyranoside ( $p N \mathrm{NPG})$, sucrose, trehalose, panose, and isomaltooligosaccharides and very low activity for maltose. The highest specific activity of $288.96 \mathrm{U} / \mathrm{mg}$ was observed for $p N P G$ at $90{ }^{\circ} \mathrm{C}$ and $\mathrm{pH} 5.0$; $\mathrm{Pb}^{2+}$ provided a $20 \%$ activity increase. TtAG was stable at $70{ }^{\circ} \mathrm{C}$ for more than $7 \mathrm{~h}$ and had a half-life of $195 \mathrm{~min}$ at $80^{\circ} \mathrm{C}$ and $130 \mathrm{~min}$ at $90^{\circ} \mathrm{C}$. Transglycosylation activity was also observed with sucrose and trehalose as substrates. TtAG showed differences on substrate specificity, transglycosylation, multimerization, effects of metal ions and optimal pH from other reported Thermus a-glucosidases. One single-substitution TtAG mutant Q10Y with improved thermostability was also obtained from random mutagenesis library. The site-saturation mutagenesis and structural modelling analysis indicated that Q10Y substitution stabilized TtAG structure via additional hydrogen bonding and hydrophobic interactions.
\end{abstract}

Conclusion: Our findings indicate that TtAG is a highly thermostable and more acidic a-glucosidase distinct from other reported Thermus a-glucosidases. And this work also provides new insights into the catalytic and thermal tolerance mechanisms of a-glucosidases, which may guide molecular engineering of a-glucosidase and other thermostable enzymes for industrial application.

\section{Background}

Glycoside hydrolases (GHs), catalyzing the hydrolysis of glycosidic linkages, are widely distributed in the natural world, and play essential roles in the carbohydrate metabolism [1]. In the CAZy database, GHs are classified into 133 families based on sequence similarity

\footnotetext{
* Correspondence: mayanhe@im.ac.cn

${ }^{1}$ State Key Laboratory of Microbial Resources, Institute of Microbiology, Chinese Academy of Sciences, No. 1 West Beichen Road, Chaoyang District, Beijing 100101, China

${ }^{2}$ National Engineering Lab for Industrial Enzymes, Institute of Microbiology, Chinese Academy of Sciences, No. 1 West Beichen Road, Chaoyang District,
} Beijing 100101, China

\section{() Biomed Central}

(c) 2015 Zhou et al. Open Access This article is distributed under the terms of the Creative Commons Attribution 4.0 International License (http://creativecommons.org/licenses/by/4.0/), which permits unrestricted use, distribution, and reproduction in any medium, provided you give appropriate credit to the original author(s) and the source, provide a link to the Creative Commons license, and indicate if changes were made. The Creative Commons Public Domain Dedication waiver (http://creativecommons.org/publicdomain/zero/1.0/) applies to the data made available in this article, unless otherwise stated. family 13 is the largest family and contains various enzymes such as $\alpha$-Amylases (EC 3.2.1.1), cyclodextrin glucanotransferases (EC 2.4.1.19), branching enzymes (2.4.1.18) and $\alpha$-glucosidases (EC 3.2.1.20). GH family 13 enzymes show low similarity within their amino acid sequences, and are further divided into 40 subfamilies [3]. They also contain four short conserved regions (regions I-IV) including essential amino acid residues for catalysis [4]. GH family 13 contains several exo-glucosidases: $\alpha-$ glucosidase, oligo-1,6-glucosidase (EC 3.2.1.10, O16G) and dextran glucosidase (EC 3.2.1.70, DG). Most of these 
enzymes show high amino acid sequence similarity, and are classified into GH family 13 subfamily 31 (GH13_31) [5].

$\alpha$-Glucosidases are typical exo-type amylolytic hydrolases that release $\alpha$-glucose from non-reducing ends of oligosaccharides and polysaccharides [6] and commonly associate with other amylolytic enzymes, which completely degrade and utilize starch as a carbon source [7]. They are widely distributed among microorganisms, plants and animals, and take part in the glycogen metabolism of higher organisms and nutrient uptake and processing of bacteria [8]. $\alpha$-Glucosidases are generally involved in the last step of starch degradation and are the second most important enzymes during the early stages of raw starch hydrolysis [9]. In addition to hydrolytic activity, some $\alpha$-glucosidases possess transglycosylation activity that could be applied to the industrial production of oligosaccharides as well as conjugation of sugars to biologically useful materials [10-14]. Specifically, there is increased interest in applying the transglycosylation activity of $\alpha$-glucosidases to the biosynthesis of bioactive compounds owing to the specificity, efficiency, and safety of the enzymatic reaction [15-18].

Numerous $\alpha$-glucosidases have been characterized, with the majority from mesophilic organisms. Industrial application of these enzymes requires stability at high temperatures as well as toward common denaturant agents, and therefore, enzymes isolated from thermophiles have gained attention over the past decade [7]. There are many thermostable $\alpha$-glucosidases from different thermophilic and hyperthermophilic microorganisms such as Sulfolobus tokodaii [7], Geobacillus toebii [19], Thermus caldophilus [20], Thermoplasma acidophilum [21], Bacillus stearothermophilus [22] and Thermus thermophilus [23, 24] have been discovered and characterized, and several mesophilic $\alpha$-glucosidases have been engineered by mutagenesis to enhance enzyme thermostability $[25,26]$.

Thermus thermophilus is a thermophilic bacterium with optimal growth temperatures of approximately $70-75{ }^{\circ} \mathrm{C}$ and produce several enzymes of considerable biotechnological interest, including proteases, phosphatases, catalases, DNA processing enzymes, and $\alpha$-glucosidases [27]. $\alpha$-Glucosidases isolated from T. thermophilus HB8, T. thermophilus HB27, and T. caldophilus GK24 have been characterised with regard to their substrate specificity $[20,23,24]$, which are different from that of the majority of known $\alpha$ glucosidases. Whereas typical enzymes favour the $\alpha-1,4$ glycosidic bonds of maltose or maltooligosaccharides [28], Thermus $\alpha$-glucosidases preferentially hydrolyse the $\alpha-1,6$ bonds in isomaltose, $\alpha-1,2$ bonds in sucrose, or $\alpha-1,1$ bonds in trehalose. In addition, they are thermostable and show transglycosylation activity with different substrates.
Thermus thermophilus TC11, isolated from a hot spring in Yunnan province of China, demonstrates high $\alpha$-glucosidase activity even at $90{ }^{\circ} \mathrm{C}$ (data not published). Herein, the $\alpha$-glucosidase (TtAG) gene from $T$. thermophilus TC11 was cloned and expressed in Escherichia coli. Some properties such as multimerization, effects of metal ions, optimal $\mathrm{pH}$, substrate specificity and transglycosylation of recombinant TtAG were different from those of the previously described Thermus $\alpha$-glucosidases, even though they have high sequence identities (>90\%). We also constructed and screened a random mutagenesis library and obtained one TtAG mutant with improved thermostability, which was analysed using site-directed mutagenesis and 3D structure modelling. Our findings further the understanding of molecular mechanisms underlying the thermostability of $\alpha$-glucosidases and may facilitate the engineering of highly thermostable enzymes for industrial applications.

\section{Results}

\section{Sequence analysis of TtAG}

The $\alpha$-glucosidase gene ttag (GenBank accession number: KP765743) cloned from $T$. thermophilus TC11 contains 1,587 bp and encodes a 528 -amino-acid protein with a predicted molecular mass of $61.8 \mathrm{kDa}$. The deduced protein sequence showed the highest homology to microbial annotated $\alpha$-glucosidases from $T$. thermophilus HB27 (GenBank No.WP_011172564), T. thermophilus HB8 (GenPept No.YP143747) and T. caldophilus GK24 (GenBank No. AF096282), oligo-1,6glucosidases from Bacillus flavocaldarius (GenBank No.BAB18518), Thermus. sp. RL (GenBank No. EIA39407) and Meiothermus silvanus DSM 9946 (GenBank No.WP_013157279) with $96 \%, 88$ \%, 87 \%, 87 \%, $87 \%$, and $70 \%$ identity, respectively. Among these six $\alpha-$ glucosidases, the enzymes from $B$. flavocaldarius, $T$. sp. RL, and M. silvanus DSM 9946 had not yet been reported. The amino acid sequence alignment of TtAG with these five enzymes (Additional file 1: Figure S1) displayed that TtAG contains the four short conserved regions as region I 95-DLVPNH, region II 193-GFRVDVLWL, region III 244-EMRQ, and region IV 321-VLGNHD, indicating that TtAG belongs to glycoside hydrolase (GH) family 13 of clan GH-H [4].

\section{Purification and properties of the recombinant TtAG}

The ttag gene was successfully expressed in E. coli BL21 (DE3), and the protein was purified to homogeneity by a two-step process, including heat treatment and His-Tag affinity chromatography. The final product showed an approximate 9.5 -fold increase in purity with a recovery of $86.5 \%$ activity relative to that of the crude enzyme (Table 1). The specific activity of the purified enzyme was $288.96 \mathrm{U} / \mathrm{mg}$ with $p \mathrm{NPG}$ as a substrate. Interestingly, the 
Table 1 Purification of recombinant TtAG

\begin{tabular}{lccccc}
\hline Preparation & Total protein $(\mathrm{mg})$ & Total activity $(\mathrm{U})$ & Yield (\%) & Specific activity (U/mg) & Purification fold \\
\hline Supernatant of crude extract & 89.4 & 2772.2 & 100.0 & 31.01 & 1.0 \\
Supernatant after heating treatment & 25.5 & 3312.0 & 119.0 & 129.88 & 4.2 \\
Affinity (His-Tag column) & 8.3 & 2398.4 & 86.5 & 288.96 & 9.3 \\
\hline
\end{tabular}

total TtAG activity did not decrease; rather, it increased by $11.9 \%$ after heating at $70{ }^{\circ} \mathrm{C}$ for $30 \mathrm{~min}$, when approximately $72 \%$ of the $E$. coli total proteins were denatured.

The purified recombinant TtAG was homogeneous with an approximate molecular mass of $60 \mathrm{kDa}$ in SDSPAGE (Additional file 1: Figure S2), which is consistent with the theoretical mass, based on the amino acid sequence. However, gel filtration chromatography showed that the molecular mass of the native TtAG was beyond the detection range of $150 \mathrm{kDa}$, indicating that native TtAG is an oligomer (Fig. 1a and b). To accurately determine the molecular mass of native TtAG, we performed dynamic light scattering (DLS) analysis, which detected a peak with a hydrodynamic radius of $5.5 \mathrm{~nm}$ (Fig. 1c), corresponding to a molecular mass of $184 \mathrm{kDa}$, suggesting that native TtAG exists in solution as a trimer, whereas the $\alpha$-glucosidase $\mathrm{AglH}_{\mathrm{HB} 27}$ from T. thermophilus HB27 is a dimer [23].

A previous study on the catalytic mechanism of $\alpha$ glucosidase from Geobacillus sp. strain HTA-462 (GSJ), which shows the highest sequence similarity with TtAG in Protein Data Bank (PDB) data base and also belongs to GH family 13, identified conserved amino acids D199, E256, and D326 as the catalytic residues and H103 and H325 as the substrate binding sites [8]. Sequence alignment demonstrated that D197, E264, D326, H100, and H325 of TtAG were highly corresponded and conserved to these sites of GSJ, respectively. Three TtAG mutants, carrying D197N, D326N and E264Q substitutions, were obtained by site-directed mutagenesis to experimentally confirm the catalytic residues, and all the three mutants were inactive. The $C D$ spectra were also checked and the gross conformation of the three mutants did not change (data not shown). So D197, D326, and E264 were considered as TtAG catalytic sites and H100 and H325 as its substrate-binding sites.

\section{Physical properties of the recombinant TtAG}

The effect of $\mathrm{pH}$ and temperature on recombinant TtAG catalytic activity was determined using $p$ NPG as a substrate. TtAG showed maximum activity at $\mathrm{pH} 5.0$ and $90{ }^{\circ} \mathrm{C}$ and retained more than $60 \%$ and $50 \%$ activity at $\mathrm{pH}$ 4.5-8.0 and temperatures of $70{ }^{\circ} \mathrm{C}-95{ }^{\circ} \mathrm{C}$, respectively. Importantly, it retained $35 \%$ activity at $100{ }^{\circ} \mathrm{C}$, but showed almost no activity below $50{ }^{\circ} \mathrm{C}$. TtAG was stable over a wide range of $\mathrm{pH}$ values $(4-9)$ at $50{ }^{\circ} \mathrm{C}$, retaining over $80 \%$ of its original activity after a 30-min incubation. TtAG also demonstrated significant thermostability; it remained fully active after a 7 -h incubation at $70^{\circ}$ $\mathrm{C}$ and showed a half-life of $210 \mathrm{~min}$ at $80{ }^{\circ} \mathrm{C}$ and $130 \mathrm{~min}$ at $90{ }^{\circ} \mathrm{C}$, suggesting that it could be a good candidate for application in industrial settings. However, the thermostability of TtAG was negatively affected by $\mathrm{NaCl}$ indicating that salt was an adverse factor for enzyme stability at high temperatures.

The effect of various metal ions and chemicals on TtAG enzymatic activity was examined after a 30 -min incubation at $50{ }^{\circ} \mathrm{C}$ and $\mathrm{pH}$ 6.0. $\mathrm{Al}^{3+}, \mathrm{Hg}^{2+}, \mathrm{Fe}^{3+}, \mathrm{Li}^{+}$,
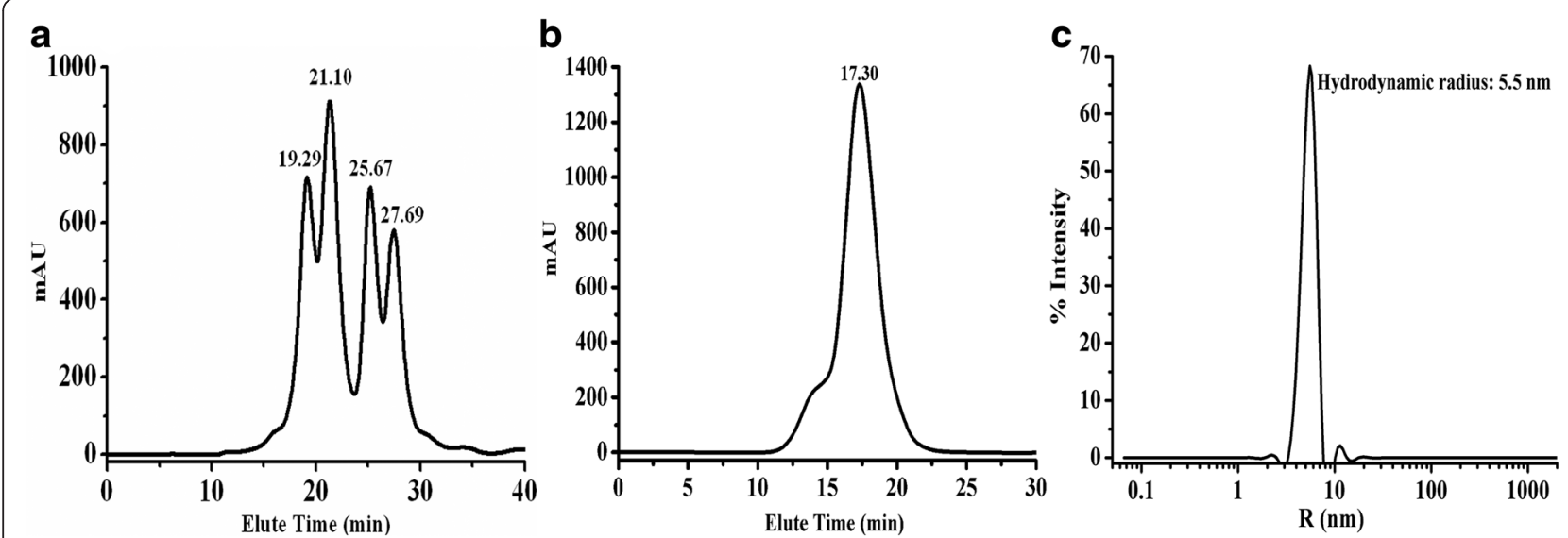

Fig. 1 The gel filtration and dynamic light scattering (DLC) of the native recombinant TtAG. a The gel filtration of molecular standard marker. b The gel filtration of the native recombinant TtAG. $\mathbf{c}$ The regularization graph of the native recombinant TtAG in DLC experiment. The Rayleigh Spheres model was used. The $x$-axis indicates the hydrodynamic radius 
$\mathrm{Ce}^{4+}, \mathrm{Ag}^{+}, \mathrm{Fe}^{2+}, \mathrm{Ni}^{2+}$, and $\mathrm{Cu}^{2+}$ significantly inhibited TtAG activity, whereas $\mathrm{Mg}^{2+}, \mathrm{Mn}^{2+}, \mathrm{Ca}^{2+}$, and EDTA had no effect, and $\mathrm{Pb}^{2+}$ produced a $20 \%$ increase. TtAG was tolerant to $8 \mathrm{M}$ urea, retaining approximately $95 \%$ activity, but was sensitive to guanidine hydrochloride and SDS, demonstrating only $20 \%$ and $30 \%$ activity after incubation with $4 \mathrm{M}$ guanidine hydrochloride and $1 \%$ SDS, respectively.

\section{Substrate specificity and Transglycosylation of TtAG}

The hydrolytic activity of TtAG with various substrates was examined at $90{ }^{\circ} \mathrm{C}$; kinetic parameters are shown in Tables 2. TtAG was capable of cleaving sucrose $(\alpha-1,2$ bond), trehalose ( $\alpha-1,1$ bond), panose ( $\alpha-1,6$ and $\alpha-1,4$ bonds), isomaltose ( $\alpha-1,6$ bond), isomaltotriose, and aryl-substrate $p$ NPG, with the highest specific activity of $288.96 \mathrm{U} / \mathrm{mg}$ for $p$ NPG (Table 2). No activity was detected for $p$-nitrophenyl- $\beta$-D-glucopyranoside, raffinose, melibiose, melezitose, maltooligosaccharides, starch, amylopectin, glycogen, pullulan, or dextrin. Very low activity $(0.5 \mathrm{U} / \mathrm{mg})$ for maltose $(\alpha-1,4$ bond) was observed only when the reaction time was increased to $2 \mathrm{~h}$ and excess enzyme was added. The $K m$ for $p$ NPG was $0.48 \mathrm{mM}$, which was lower than that for the other substrates. The TtAG substrate preference was as follows: $p$ NPG $>$ isomaltotriose $>$ isomaltose $>$ trehalose $>$ panose $>$ sucrose $\left(k_{\text {cat }} / K m\right.$ values of $1372.08,12.15,9.39,7.02$, 4.87, and $2.46 \mathrm{~s}^{-1} \cdot \mathrm{mM}^{-1}$, respectively; Table 2). Among natural substrates, TtAG showed higher specificity for isomaltooligosaccharide than for other oligosaccharides. Overall, these results indicate that TtAG acts as an oligo-1,6-glucosidase, which is consistent with the characteristics of GH13 $\alpha$-glucosidases. $\alpha$-glucosidases are further classified into three types according to their substrate specificity. Type I hydrolyses aryl glucosides such as $p$ NPG faster than short malto-oligosaccharides. However, Type II is more active on maltose and has low activity towards aryl glucosides, whereas Type III resembles Type II, but hydrolyses oligosaccharides and starch at similar rates [29]. From this substrate specificity, TtAG belongs to Type I $\alpha$-glucosidase.

Table 2 Kinetic parameters of recombinant TtAG for hydrolysis of various substrates

\begin{tabular}{llll}
\hline Substrate & $K_{m}(\mathrm{mM})$ & $K_{\text {cat }}\left(\mathrm{s}^{-1}\right)$ & $K_{\text {cat }} / K_{m}\left(\mathrm{~s}^{-1} \mathrm{mM}^{-1}\right)$ \\
\hline pNPG & 0.48 & 658.60 & 1372.08 \\
Sucrose & 30.53 & 74.64 & 2.46 \\
Trehalose & 19.96 & 140.04 & 7.02 \\
Panose & 18.57 & 90.42 & 4.87 \\
Isomaltose & 10.59 & 99.51 & 9.39 \\
Isomaltotriose & 15.58 & 189.3 & 12.15 \\
Maltose & $\mathrm{n} \mathrm{d.}$ & $\mathrm{n} \mathrm{d}$. & $\mathrm{n} \mathrm{d}$. \\
\hline
\end{tabular}

To determine whether TtAG could perform transglycosylation, it was incubated with $300 \mathrm{mM}$ isomaltotriose, isomaltose, trehalose, panose, and sucrose for $3 \mathrm{~h}$. TLC analysis of the reaction products revealed transglycosylation activity only with sucrose or trehalose as substrates. Further analysis of TtAG transglycosylation activity with trehalose and sucrose showed that the yield of transglycosylation products increased with the incubation time (up to 20 h; Fig. 2a). The transglycosylation activity of TtAG was confirmed by detection of reaction products after TtAG incubation with $300 \mathrm{mM}$ sucrose or trehalose for $20 \mathrm{~h}$. HPLC analysis revealed three major peaks corresponding to sucrose, glucose, and fructose, and two minor peaks corresponding to the products of a transglycosylation reaction with sucrose (Fig. 2b); similarly, a small peak indicating a transglycosylation product was detected after TtAG reaction with trehalose (Fig. 2c).

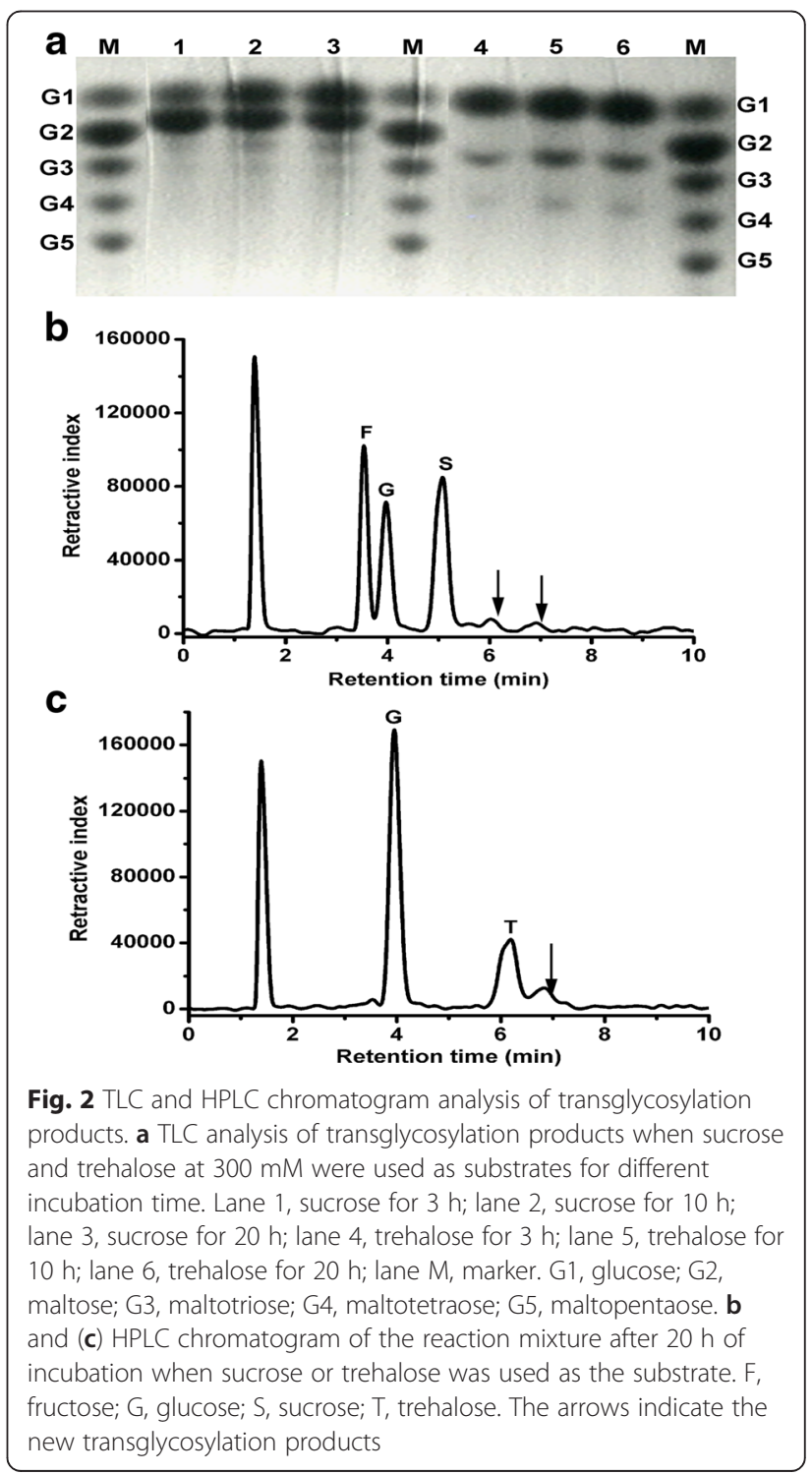


These results further confirmed the transglycosylation activity of TtAG with sucrose and trehalose.

\section{Screening and biochemical properties of TtAG mutants with improved thermostability}

Random mutagenesis by error prone PCR (ep-PCR) was used to get thermostability improved variant of TtAG. The ep-PCR library constructed using the MEGAWHOP method [30] contained approximately $30 \%$ inactive TtAG variants. In general, one to five nucleotide mutations per gene were observed. The library was expressed using the auto induction system; the standard deviation was $12.8 \%$, which conforms to the $10 \%$ standard deviation in screening systems successfully used in directed evolution experiments [31, 32]. The activity ratio of heat-treated to untreated bacteria was designated as residual activity and used to select mutants with improved thermostability; the selection criterion was an increase of at least $10 \%$ in the residual activity of a mutant compared to the wild type after heat treatment. Approximately 2,700 ep-PCR library clones were screened and one mutant with increased thermostability carrying a single amino acid substitution of Q10Y was selected. Under the screening conditions, the residual activity ratio of the wild-type TtAG was approximately $15 \%$, whereas that of Q10Y mutant was approximately $38 \%$.

The Q10Y mutant and wild-type TtAG were expressed in E. coli BL21 (DE3) and their thermostability was determined based on $\mathrm{T}_{50}^{15}$ and $\Delta \mathrm{T}_{50}^{15}$ values. The $\mathrm{T}_{50}^{15}$ of Q10Y was $97{ }^{\circ} \mathrm{C}$, with $\Delta \mathrm{T}_{50}^{15}$ of $4{ }^{\circ} \mathrm{C}$ compared to the wild-type TtAG $\left(\mathrm{T}_{50}^{15}\right.$ of $\left.93{ }^{\circ} \mathrm{C}\right)$. These results indicate that the thermostability of the Q10Y mutant was significantly increased compared to that of the wild-type enzyme. The substrate specificity of Q10Y mutant was also determined as similar to the wild-type TtAG (data not shown). The hydrolytic activity and kinetic parameters of the mutated and wild-type enzymes were determined at the optimal reaction conditions. The specific activity of Q10Y with $p$ NPG was $236.9 \mathrm{U} / \mathrm{mg}$ which decreased to approximately $82 \%$ of that of wild-type TthAG, indicating that the increase in thermostability was accompanied by a loss of enzymatic activity. The $\mathrm{Km}$ of Q10Y was $0.46 \mathrm{mM}$ and similar to that of the wild-type indicating similar substrate binding ability. However, the $k_{\text {cat }}$ of Q10Y $\left(356.57 \mathrm{~s}^{-1}\right)$ decreased $46 \%$ which resulted in about $44 \%$ decrease of the $k_{c a t} / K m$ ratio $\left(775.15 \mathrm{~s}^{-1} \mathrm{mM}^{-1}\right)$. These data indicate that the mutation of Q10Y affected not only the thermostability but also the catalytic activity of TtAG, suggesting that the mutated residue are located in close proximity to the active and/or substrate-binding sites and can affect catalysis. In order to further confirm the influence of Q10 site for thermostability, saturation mutagenesis of the Q10 site was done by site-directed mutagenesis. The results demonstrated that the $\mathrm{T}_{50}^{15}$ values of all 18 other mutants carrying single amino acid substitutions decreased compared to that of the wild-type enzyme (data not shown), which means that only the Q10Y substitution in this site improved the thermostability of TtAG. This single substitution Q10Y was firstly reported responsible for improvement of the thermal tolerance of $\alpha$-glucosidase, and may help for guiding molecular engineering of other $\alpha$-glucosidases for thermostability improvement.

\section{Discussion}

In this study, we successfully expressed, purified and characterized the thermostable $\alpha$-glucosidase TtAG from T. thermophilus TC11. Although TtAG and other reported Thermus $\alpha$-glucosidases similarly cannot hydrolyse the disaccharides cellobiose and melibiose or the trisaccharides raffinose and melizitose and are inactive for polysaccharides such as starch, amylopectin, glycogen, pullulan, and dextrin, there are still many differences in biochemical properties and substrate specificity between TtAG and other Thermus $\alpha$-glucosidases, even though they demonstrate more than $90 \%$ similarity with respect to amino acid sequence. $\mathrm{Ca}^{2+}$ can activate the $\alpha$ glucosidases $\mathrm{AglH}_{\mathrm{HB} 27}$ and $\mathrm{AglH}_{\mathrm{HB} 8}$ from T. thermophilus HB8 and TcaAG from T. thermophilus GK24, whereas $\mathrm{Pb}^{2+}$ inhibits their activity. In contrast, TtAG is activated by $\mathrm{Pb}^{2+}$, whereas $\mathrm{Ca}^{2+}$ has no effect. $\mathrm{Pb}^{2+}$, as a heavy metal ion, generally inhibits the activity of most enzymes, including $\alpha$-glucosidases $[14,24]$. Therefore, TtAG activation by $\mathrm{Pb}^{2+}$ may indicate an interesting property different from that of other $\alpha$-glucosidases. However, about this experimental observation, we actually cannot understand why based on our current knowledge. The optimal $\mathrm{pH}$ for TtAG activity is 5.0, whereas that for $\mathrm{AglH}_{\mathrm{HB} 8}, \mathrm{AglH}_{\mathrm{HB} 27}$, and TcaAG was higher (5.8, 6.2 , and 6.5 , respectively) $[20,23,24]$, suggesting increased acid resistance. Although TtAG is similar to the other three Thermus $\alpha$-glucosidases in terms of optimal temperature $\left(90{ }^{\circ} \mathrm{C}\right)$ and $\mathrm{pH}$ tolerance, it demonstrates significant variations in other properties, indicating that TtAG is an $\alpha$-glucosidase with distinct biochemical characteristics.

The substrate specificity and catalytic efficiency of TtAG and other reported Thermus $\alpha$-glucosidases are summarized in Table 3. Similar to $\mathrm{AglH}_{\mathrm{HB} 27}$, TtAG can hydrolyse trehalose ( $\alpha$-1,1-glucosidic linkage). However, the activity of $\mathrm{AglH}_{\mathrm{HB} 27}$ for isomaltose $(\alpha-1,6)$, isomaltotriose, and sucrose $(\alpha-1,2)$ was only $63.8 \%, 30.5 \%$, and $8.0 \%$ of that for trehalose [23], while the activity of TtAG for the same substrates was $96.5 \%, 181.6 \%$ and $46.1 \%$, respectively, indicating a preference of TtAG for isomaltotriose over trehalose, which is different from the substrate specificity of $\mathrm{AglH}_{\mathrm{HB} 27}$. In contrast to TtAG and $\mathrm{AglH}_{\mathrm{HB} 27}$, the $\alpha$-glucosidase $\mathrm{AglH}_{\mathrm{HB} 8}$ and TcaAG cannot hydrolyse trehalose [20,24] and prefer isomaltose, 
Table 3 Substrate specificity for oligosaccharides of a-glucosidase TtAG, AglH $\mathrm{HB}_{27}, \mathrm{AglH}_{\mathrm{HB} 8}$ and TcaAG from Thermus strains

\begin{tabular}{|c|c|c|c|c|c|}
\hline \multirow[t]{2}{*}{ Substrate } & \multirow[t]{2}{*}{ Glycosidic linkage } & \multicolumn{4}{|c|}{ Relative activity (\%) } \\
\hline & & TtAG & $\mathrm{AgIH}_{\mathrm{HB} 27}$ & $\mathrm{AglH}_{\mathrm{HB} 8}$ & TcaAG \\
\hline Sucrose & Glu-a-1,2-Fru & $47.8(46.1)$ & $12.5(8.0)$ & 8.4 & 59.3 \\
\hline Trehalose & Glu-a-1,1-Glu & $103.7(100.0)$ & $156.7(100.0)$ & 0.0 & 0.0 \\
\hline Isomaltose & Glu-a-1,6-Glu & $100.0(96.5)$ & $100.0(63.8)$ & 100.0 & 100.0 \\
\hline Cellobiose & Glu- $\beta-1,4-G l u$ & 0.0 & 0.0 & 0.0 & 0.0 \\
\hline Melibiose & Gla-a-1,6-Glu & 0.0 & 0.0 & 0.0 & 0.0 \\
\hline Maltose & Glu-a-1,4-Glu & $3.7(3.5)$ & $15.1(9.7)$ & 2.8 & 1.6 \\
\hline Melizitose & Glu-[a-1,3]-Fru- $\beta-2,1-G l u$ & 0.0 & 0.0 & 0.0 & 0.0 \\
\hline Isomaltotriose & Glu-[a-1,6]-Glu-a-1,6-Glu & $188.2(181.6)$ & $47.8(30.5)$ & 45.2 & 4.8 \\
\hline Raffinose & Gla-[a-1,6]-Glu-a-1,2-Glu & 0.0 & 0.0 & 0.0 & 0.0 \\
\hline Panose & Glu-[a-1,6]-Glu-a-1,4-Glu & $62.5(60.3)$ & $56.1(35.8)$ & 42.1 & 44.6 \\
\hline
\end{tabular}

whereas TtAG and $\mathrm{AglH}_{\mathrm{HB} 27}$ are most active with $p$ NPG and trehalose, respectively. Meanwhile, all these four enzymes belong to Type I $\alpha$-glucosidases according to their substrate specifities. The activity towards sucrose may made TtAG has potential application in high fructose syrup production.

The transglycosylation activity reported for many $\alpha$ glucosidases has been exploited in biotechnology to produce food oligosaccharides or to conjugate sugars with biologically active materials [14]. $\mathrm{AglH}_{\mathrm{HB} 27}$ catalyses transglycosylation only in the presence of higher levels of trehalose or isomaltose and incubation for up to $24 \mathrm{~h}$, whereas TcaAG shows transglycosylation activity only with sucrose or isomaltose; however, TtAG demonstrated transglycosylation with sucrose and trehalose after only $3 \mathrm{~h}$, suggesting higher transglycosylation activity compared to that of other Thermus $\alpha$-glucosidases. Although TtAG shares approximately $90 \%$ amino acid sequence identity with the homologous enzymes from $T$. thermophilus strains HB27 and HB8 and T. caldophilus GK24, it has different substrate specificity, catalytic efficiency (Table 3), and transglycosylation activity. It has been suggested that enzymes with high amino acid identity but different substrate specificity may have evolved through a limited number of amino acid substitutions to give rise to enzymes with broader substrate specificity or other related activities [33].

The CD spectra were analyzed to determine whether the mutation affected the secondary structure. The results showed that there were no distinct changes between wild-type TtAG and the Q10Y mutants (Fig. 3). This meant that the thermostability improvements were not caused by secondary structural change. The TtAG mutant Q10Y demonstrated increased thermostability but decreased enzymatic activity. To determine how the Q10Y mutation affected TtAG thermostability, the 3D structure of TtAG was modelled based on the structure of $\alpha$-glucosidase GSJ from Geobacillus sp. strain HTA-
462 (PDB:2ze0) as a template, using the SWISS-MODEL software online. The PROCHECK analysis showed that $90.9 \%$ of the residues were in the most favoured regions and $8.7 \%$ of the residues were in additional regions, indicating the reliability of the modelled structure. As shown in Fig. 4a, Q10 is located in the $\beta$-barrel of the catalytic domain, in close proximity to the catalytic and substrate-binding sites D326 and H325, respectively; therefore, Q10Y substitution would probably influence TtAG substrate binding and/or catalytic efficiency, resulting in a decrease in enzymatic activity. Q10Y substitution in the TtAG catalytic centre enhances TtAG thermostability, probably by stabilisation of the catalytic domain. In the structure of the homologous enzyme GSJ, a hydrogen bond is formed between Q13 and I361, located on different $\beta$-sheets [8]. In TtAG, the homologous amino acids Q10 and W355, respectively, are also located on two adjacent $\beta$-sheets with the distance of $2.8 \AA$ (Fig. 4b), which is sufficient for the formation of a hydrogen bond. Similarly, hydrogen bonds can be

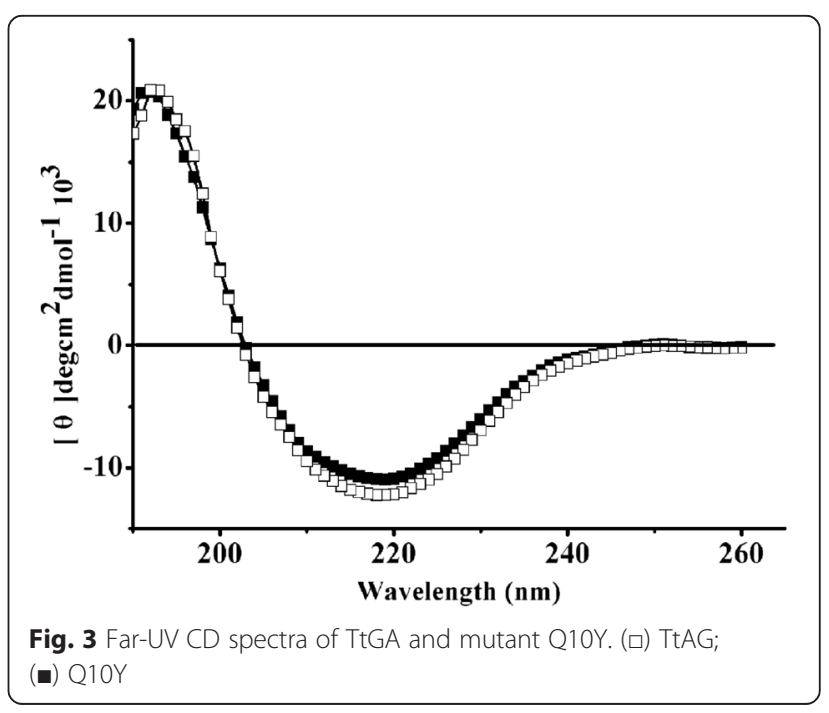




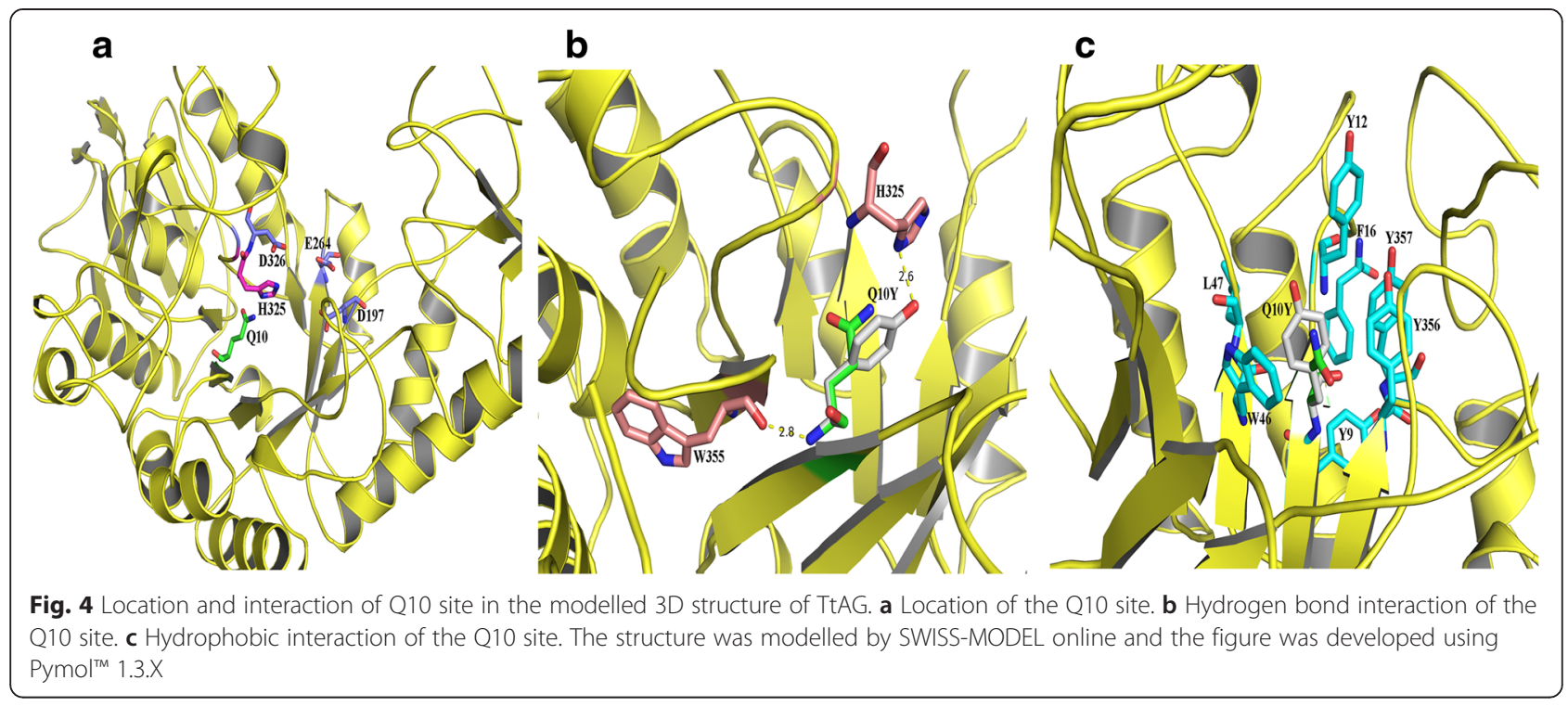

formed between the amino group of Y10 and the carboxyl of W355 and between the hydroxyl of Y10 benzene ring and the amino group of His325, which are also located in the adjacent $\beta$-sheets with a distance of $2.6 \AA$ (Fig. 4b). Saturation mutagenesis of the Q10 site demonstrated that the $\mathrm{T}_{50}^{15}$ values of all 18 other mutants carrying single amino acid substitutions (except Q10Y) decreased compared to that of the wild-type enzyme, likely because the mutated proteins could not form additional hydrogen bonds. Because hydrogen bonding is considered to directly influence protein thermostability [34], we hypothesize that additional hydrogen bonding in the Q10Y mutant could account for its increased thermostability. In addition, among the other 18 saturation mutants, only Q10E demonstrated the same enzymatic activity as the wild type TtAG (data not shown), probably because of similarities in terms of structure and size between glutamine and glutamic acid, which differ only in charge (neutral for $\mathrm{Q}$ and negative for E), suggesting an important role of Q10 for TtAG enzymatic activity.

Q10 is located also close to a possible hydrophobic core formed by Y9, Y12, F16, W46, L47, Y356, and Y357 (Fig. 4c). A previous study determined that the hydrophobic amino acid content is marginally higher in thermophiles than in mesophiles, which can increase protein rigidity and hydrophobicity [35], thus suggesting a role of hydrophobic interactions in protein thermostability [36-38]. Tyrosine is more hydrophobic than glutamine; hence, Q10Y substitution may strengthen hydrophobic interactions between this and other tyrosines of the TtAG hydrophobic core, resulting in enhanced thermostability. However, even though some other amino acids are more hydrophobic than glutamine, only the substitution of Q10Y stabilized TtAG; therefore, we suggest that a combination of hydrogen bonding and hydrophobic interactions of mutation Q10Y resulted in improved thermostability for TtAG.

\section{Conclusions}

In summary, a highly thermostable and acidic $\alpha$ glucosidase, TtAG, from T. thermophilus TC11 was cloned, expressed, and characterized. Although TtAG shares approximately $90 \%$ amino acid identity with the homologous $\alpha$-glucosidases from other $T$. thermophilus strains, it has distinct biochemical characteristics, which indicates that TtAG is an $\alpha$-glucosidase with potential biotechnological applications. The TtAG mutant carrying the single amino acid substitutions Q10Y demonstrated enhanced thermostability. Structure modelling and site-directed mutagenesis demonstrated that hydrogen bonding and hydrophobic interactions were responsible for the increased thermostability imparted by Q10Y. Our findings provide new insights into the catalytic and thermal tolerance mechanisms of $\alpha$-glucosidases, which may guide molecular engineering of thermostable enzymes for industrial applications. Furthermore, crystallization and real 3D structure resolution of TtAG in the future would deepen the understanding of catalysis by $\alpha$-glucosidase and facilitate the thermal adaptation of thermostable enzymes.

\section{Materials and methods}

Strains, plasmids, and media

Thermus thermophilus TC11, isolated from the hot spring of Tengchong in the Yunnan province of China, was obtained from the China General Microbiological Culture Collection Center (CGMCC 1.15099) and used as DNA source for cloning of the $\alpha$-glucosidase (TtAG) gene. 
pET28a and Escherichia coli BL21 (DE3) (Novagen, USA) were used for gene expression. All of the restriction enzymes used in molecular procedures were from TaKaRa Biotechnology (Dalian, China). DpnI was from New England Biolabs (Ipswich, USA). The oligosaccharides were from Sigma-Aldrich (St. Louis, USA). The isopropyl$\beta$-D-thiogalactopyranoside (IPTG), kanamycin, imidazole and protein denaturants were from Merck (Darmstadt, Germany). All the other chemicals used were of reagent grade.

\section{Construction of expression plasmid and transformation of cells}

The TtAG gene (ttag) was amplified from the genomic DNA of Thermus thermophilus TC11 by PCR with a primer pair of the forward (5'-GCTAGCTAGCATGCTTC AAAGAAC-3', where the underline indicates the NheI site) and the reverse (5'-CCGGAATTCCTATTTCACT ACAATC- ${ }^{\prime}$, the underline indicates the EcoRI site) and pfu DNA polymerase (Takara). The PCR product was purified using the Gel Extraction Kit (OMEGA Bio-tek, USA) and then digested with NheI and EcoRI to insert the digested pET28a vector. The resultant recombinant plasmid, pET28a-ttag, was transformed into E. coli BL21 (DE3) for gene expression.

\section{Gene expression and protein purification}

E. coli BL21 (DE3) harbouring the recombinant plasmid was cultured in $0.5 \mathrm{~L}$ of LB medium containing kanamycin $(60 \mu \mathrm{g} / \mathrm{ml})$ until the $\mathrm{OD}_{600}$ reached 0.6. IPTG was added at a final concentration of $1 \mathrm{mM}$, and the cells were continuously cultivated at $37^{\circ} \mathrm{C}$ for $5 \mathrm{~h}$. Cells were harvested by centrifugation at $6,000 \times \mathrm{g}$ at $4{ }^{\circ} \mathrm{C}$ for $15 \mathrm{~min}$, washed with binding buffer $(20 \mathrm{mM}$ Tris- $\mathrm{HCl}$ buffer containing $500 \mathrm{mM} \mathrm{NaCl}$ and $5 \mathrm{mM}$ imidazole, $\mathrm{pH}$ 7.9) and then suspended in $50 \mathrm{ml}$ of the same buffer. The suspended cells were disrupted by sonication and the supernatant was obtained by centrifugation at $12,000 \times \mathrm{g}$ for $20 \mathrm{~min}$ at $4{ }^{\circ} \mathrm{C}$. The supernatant was incubated at $70{ }^{\circ} \mathrm{C}$ for $30 \mathrm{~min}$ and then centrifuged at $12,000 \times \mathrm{g}$ for $30 \mathrm{~min}$ at $4{ }^{\circ} \mathrm{C}$. The second supernatant was loaded onto a His•Bind column (5PKG) (Novogen, Germany). The column was washed with $10 \mathrm{ml}$ of binding buffer and subsequently with $15 \mathrm{ml}$ of washing buffer $(20 \mathrm{mM}$ Tris- $\mathrm{HCl}$ buffer containing $500 \mathrm{mM} \mathrm{NaCl}$ and $60 \mathrm{mM}$ imidazole, $\mathrm{pH}$ 7.9). Finally, the protein was eluted with $3 \mathrm{ml}$ of elution buffer $(20 \mathrm{mM}$ Tris- $\mathrm{HCl}$ buffer containing $500 \mathrm{mM} \mathrm{NaCl}$ and $1 \mathrm{M}$ imidazole, $\mathrm{pH}$ 7.9). The obtained protein solution was desalted using a desalting column (GE Healthcare, England) with $20 \mathrm{mM}$ Tris-HCl buffer ( $\mathrm{pH}$ 7.5). The protein concentration was determined using the Bradford method [39] with bovine serum albumin as a standard. The purity of the protein was examined by SDS-PAGE and stained by Coomassie Brilliant Blue.

\section{Molecular mass determination and circular dichroism spectra}

The apparent molecular mass of the recombinant enzyme was determined by both gel filtration chromatography Superdex 10/300 colum using cytochrome c $(12.4 \mathrm{kDa})$, carbonic anhydrase $(29 \mathrm{kDa})$, bovine serum albumin $(66 \mathrm{kDa})$ and alcohol dehydrogenase $(150 \mathrm{kDa})$ (Sigma, St. Louis, U.S.A.) as molecular mass standard. The DynaPro dynamic light scattering (DLC) systems (Wyatt Technology, USA) were also used to determine the molecular mass and the multimerization state of the native recombinant TtAG. $0.1 \mathrm{mg} / \mathrm{ml}$ of TtAG in $20 \mathrm{mM}$ Tris- $\mathrm{HCl}$ buffer ( $\mathrm{pH}$ 7.5) was used and the DLC experiment was performed at $25{ }^{\circ} \mathrm{C}$. The accurate molecular mass was obtained by hydrodynamic radium of the peak resulted by native recombinant TtAG. The monomer molecular mass was calculated from the putative amino acid sequence and estimated by SDS-PAGE.

Circular dichroism (CD) spectra of pure recombinant TtAG and the improved mutants were measured using the Jasco J-810 spectropolarimeter (Jasco, Japan) over a wavelength ranging from 190 to $260 \mathrm{~nm}$ under constant nitrogen flush. The bandwidth was set to $1 \mathrm{~nm}$. The secondary structure content of the enzyme was estimated using the program JASCOW32. All spectra were recorded at room temperature, and three scans were averaged and blank-subtracted to give the spectra.

\section{Effect of $\mathrm{pH}$, temperature and chemicals on enzyme activity and stability}

The optimal $\mathrm{pH}$ was assayed at $90{ }^{\circ} \mathrm{C}$ in $0.1 \mathrm{M}$ citric acid-0.2 M sodium phosphate buffer ( $\mathrm{pH}$ 4.0-8.0) with $0.5 \mathrm{mM} \quad p$-Nitrophenyl- $\alpha$-D-glucopyranoside ( $p \mathrm{NPG}$ ). The effect of $\mathrm{pH}$ on enzyme stability was analyzed with enzyme being incubated in buffer from $\mathrm{pH} 3-11$ at $50{ }^{\circ} \mathrm{C}$ for $30 \mathrm{~min}$. The optimal temperature was assayed at 50$98{ }^{\circ} \mathrm{C}$ for 10 minutes with standard reaction buffer (citric acid $(0.1 \mathrm{M})$-sodium phosphate $(0.2 \mathrm{M})$ buffer, $\mathrm{pH}$ 5.0). Thermal stability was analyzed by assessing enzyme activity after incubation at $70{ }^{\circ} \mathrm{C}, 80^{\circ} \mathrm{C}$ and $90^{\circ} \mathrm{C}$ for continuous time. To determine the effects of chemicals, the enzyme $(0.1 \mathrm{mg} / \mathrm{ml})$ was incubated with various metal ions and EDTA of $5 \mathrm{mM}$, and protein denatures of different concentration at $50{ }^{\circ} \mathrm{C}$ for $30 \mathrm{~min}$. The residual activity was measured under the standard hydrolytic assay condition.

\section{Standard hydrolytic activity assays}

$\alpha$-Glucosidase hydrolytic activity was determined by measuring the release of $p$-nitrophenol from $p$ NPG at $90{ }^{\circ} \mathrm{C}$ for $10 \mathrm{~min}$ in standard reaction buffer. The 
reaction was terminated by addition of equal volume of $1 \mathrm{M} \mathrm{Na}_{2} \mathrm{CO}_{3}$ solution. The absorbance of the liberated $p$-nitrophenol was measured at $410 \mathrm{~nm}$. One unit of activity was defined as the amount of enzyme liberating $1 \mu \mathrm{mol}$ of $p$-nitrophenol in one minute.

The activity on oligosaccharides and polysaccharides was determined by measuring the release of glucose at $90{ }^{\circ} \mathrm{C}$ for 15 min with $0.5 \%$ (w/v) substrates in standard reaction buffer. Reactions were terminated by incubation for $10 \mathrm{~min}$ in ice water bath. Glucose was assayed with the glucose oxidase reagent from a glucose assay kit (Sigma Diagnostics no. 510). One unit of activity was defined as the amount of enzyme liberating $1 \mu \mathrm{mol}$ of glucose in one minute.

\section{Transglycosylation activity analysis}

The transglycosylation activity was determined using $5 \mu \mathrm{g}$ of purified enzyme and $300 \mathrm{mM}$ maltose, sucrose, or trehalose in the standard reaction buffer at $75{ }^{\circ} \mathrm{C}$. After different time intervals, the reaction was terminated in a boiling water bath for $10 \mathrm{~min}$. After centrifugation $(10,000 \times \mathrm{g}, 10 \mathrm{~min}), 1-\mu \mathrm{l}$ samples were spotted on Silica Gel 60 plates (Merck, Germany) and thin-layer chromatography (TLC) analysis was performed as described previously by Kanda et al. [40]. Transglycosylation product analysis was conducted by HPLC using a $4.6 \mathrm{~mm} \mathrm{ID} \times 150 \mathrm{~mm}$ Zorbax Carbohydrate Analysis column (Agilent Technology, USA) with acetonitrile/water $(75 / 25, \mathrm{v} / \mathrm{v})$ as the mobile phase at $2 \mathrm{ml} / \mathrm{min}$ and a refractive index detector. The column temperature was kept constant at $30{ }^{\circ} \mathrm{C}$.

\section{Random mutagenesis library construction and screening}

Random mutagenesis was performed by the standard error-prone PCR (ep-PCR) method with primers pairs (forward, 5' -ATGCTTCAAAGAAC-3'; reverse, 5' -CTA TTTCACTACAATC-3') and the plasmid pET28a-ttag as the template. The PCR amplification reactions were conducted with rTaq DNA polymerase (Takara) and $\mathrm{Mn}^{2+}$ added at $0.4 \mathrm{mM}$. The PCR products were purified using a Gel Extraction Kit (OMEGA Bio-tek, USA). The purified ep-PCR products were cloned into the expression plasmid pET28a by Phusion Hot Start DNA polymerase (Finzyme) following the Megaprimer PCR of Whole Plasmid (MEGAWHOP) method [30] with plasmid pET28a-ttag as a template. Following PCR, DpnI was added and the mixture was incubated overnight at $37^{\circ} \mathrm{C}$. The MEGAWHOP products were then transformed into $E$. coli BL21 (DE3) for expression and screening.

Colonies grown on LB-kanamycin $(60 \mu \mathrm{g} / \mathrm{ml})$ agar plates were transferred, by using toothpicks, into 96-well microtiter plates containing $150 \mu \mathrm{l}$ of MDG noninducing medium [41] in each well supplemented with kanamycin $(60 \mu \mathrm{g} / \mathrm{ml})$. Two wells of each 96-well microtiter plate contained wild-type TtAG colonies. After $20 \mathrm{~h}$ of cultivation in a microtiter plate shaker (Multitron II, Infors $\mathrm{GmbH}, 37{ }^{\circ} \mathrm{C}, 900 \mathrm{rpm}, 70$ \% humidity), each well was replicated by using a replicator (EnzyScreen BV, Leiden, Netherlands) into a second series of 96-well microtiter plates containing $150 \mu \mathrm{l}$ of induction medium MD-5052 [41] supplemented with kanamycin $(60 \mu \mathrm{g} / \mathrm{ml})$. The first set of plates was stored at $-80{ }^{\circ} \mathrm{C}$ after addition of glycerol. The clones in the second set of plates were cultivated for $15 \mathrm{~h}$ in the microtiter plate shaker and used for screening.

A 20-fold dilution of the cell culture $(30 \mu \mathrm{l})$ was transferred into a 96-well PCR plate and then incubated at $99{ }^{\circ} \mathrm{C}$ for $60 \mathrm{~min}$ in a thermal cycler (Mastercyler gradient; Eppendorf); then, $5 \mu \mathrm{l}$ of the incubated cell culture was transferred into another 96-well PCR plate with $70 \mu \mathrm{l}$ of $\mathrm{Na}_{2} \mathrm{HPO}_{4}$-citric acid buffer including $0.5 \mathrm{mM}$ $p$ NPG ( $\mathrm{pH} 5.5$ ) in each well. The reaction was performed at $90{ }^{\circ} \mathrm{C}$ for $5 \mathrm{~min}$ and then terminated by addition of $75 \mu \mathrm{l}$ of $1 \mathrm{M} \mathrm{Na}_{2} \mathrm{CO}_{3}$ solution. The residual activity was determined by the absorbance at $410 \mathrm{~nm}$. Mutants in which the residual activity (\%) was at least $10 \%$ higher than that of the wild-type enzyme were preliminarily considered to have improved thermostability.

\section{Thermostability determination of wild-type and mutant enzymes}

The mutant enzymes with potential improvement of thermostability were expressed and purified as described above. $\mathrm{T}_{50}^{15}$ and $\Delta \mathrm{T}_{50}^{15}\left(\mathrm{~T}_{50}^{15}\right.$ was the temperature at which the enzyme retained $50 \%$ of the initial activity, and $\Delta \mathrm{T}_{50}^{15}$ was the difference between $\mathrm{T}_{50}^{15}$ of the mutant and wildtype enzymes) were used to evaluate the thermostability of wild-type and mutant $\alpha$-glucosidases according to the method of Eijsink et al. [42]. The purified recombinant wild-type enzyme (TtAG) and other mutated enzymes were incubated for $15 \mathrm{~min}$ at $90{ }^{\circ} \mathrm{C}$ to $99{ }^{\circ} \mathrm{C}$ at a concentration of $2 \mu \mathrm{g} / \mathrm{ml}$ in $20 \mathrm{mM}$ sodium phosphate buffer (pH 7.5). The residual activity of the heated solution was assessed as described above.

\section{D structure modeling and site mutagenesis}

The tertiary structure of TtAG was modeled by SWISSMODEL server on line (http://swissmodel.expasy.org/), using the structure of $\alpha$-glucosidase GSJ from Geobacillus sp. strain HTA-462 (PDB: 2ze0) as a template, which showed the highest identity with TtAG in the PDB database and also belongs to GH family 13 . Figures were developed using Pymol ${ }^{\text {Ta }}$ 1.3.X. The reliability of the modelled structure of TtAG was checked by PROCHECK software online (http://www.ebi.ac.uk/thornton-srv/software/ PROCHECK/). Site mutagenesis was done using the QuikChange ${ }^{\circ}$ Site-Directed Mutagenesis Kit (Stratagene, USA). The recombinant plasmid, pET28a-ttag, was used as the 
template. The mutagenesis PCR products were transformed into E. coli XL1-Blue (Novagen) directly after DpnI digestion. DNA sequencing was performed by SinoGenoMax Co., Ltd, China. The correct mutant plasmid was then transformed into E. coli BL21 (DE3) for expression.

\section{Additional file}

Additional file 1: Figure S1. Multiple amino acid sequence alignment. Figure S2. SDS-PAGE analysis of recombinant TtAG at different stages of purification. (DOCX $985 \mathrm{~kb}$ )

\section{Competing interests}

The authors declare that they have no competing interests.

\section{Authors' contributions}

$C Z$ designed and performed the experiments and drafted the manuscript. YX helped to analyze the data and revise the manuscript. YM directed the over-all study and had given final approval of the version to be published. All authors had read and approved the final manuscript.

\section{Acknowledgements}

This work was financially supported by the National Basic Research Program of China (2011CBA00805), Chinese National Programs for High Technology Research and Development (2012AA022204) and the Key Research program of Chinese Academy of Science (KSZD-EW-Z-015-2).

\section{Received: 3 April 2015 Accepted: 19 August 2015}

\section{Published online: 21 October 2015}

\section{References}

1. Saburi W, Rachi-Otsuka H, Hondoh H, Okuyama M, Mori H, Kimura A Structural elements responsible for the glucosidic linkage-selectivity of a glycoside hydrolase family 13 exo-glucosidase. FEBS Lett. 2015;589:865-9.

2. Cantarel BL, Coutinho PM, Rancurel C, Bernard T, Lombard V, Henrissat B The Carbohydrate-Active EnZymes database (CAZy): an expert resource for Glycogenomics. Nucleic Acids Res. 2009;37:D233-238.

3. Stam MR, Danchin EG, Rancurel C, Coutinho PM, Henrissat B. Dividing the large glycoside hydrolase family 13 into subfamilies: towards improved functional annotations of a-amylase-related proteins. Protein Eng Des Sel. 2006;19:555-62.

4. Ryoichi N, Tadayuki I, Shuichi A. Comparison of amino acid sequences of eleven different a-amylases. Appl Microbiol Biotechnol. 1986;23:355-60.

5. MacGregor EA, Janecek S, Svensson B. Relationship of sequence and structure to specificity in the a-amylase family of enzymes. Biochim Biophys Acta. 2001:1546:1-20.

6. Krasikov W, Karelov DV, Firsov LM. a-Glucosidase. Biochemistry (Moscow) 2001:66:267-81.

7. Park JE, Park SH, Woo JY, Hwang HS, Cha J, Lee H. Enzymatic properties of a thermostable a-glucosidase from acidothermophilic crenarchaeon Sulfolobus tokodaii strain 7. J Microbiol Biotechnol. 2013;23(1):56-63.

8. Shirai T, Hung VS, Morinaka K, Kobayashi T, Ito S. Crystal structure of GH13 alpha-glucosidase GSJ from one of the deepest sea bacteria. Proteins. 2008;73(1):126-33.

9. Emmanuel L, Stefan J, Bernard H, Abdel B. Thermophilic archaeal amylolytic enzymes. Enzyme Microb Tech. 2000;26:3-14.

10. Crittenden RG, Playne MJ. Production, properties and applications of foodgrade oligosaccharides. Trends Food Sci Tech. 1996;7:353-61.

11. Hung VS, Hatada Y, Goda S, Lu J, Hidaka Y, Li Z, et al. a-Glucosidase from a strain of deep-sea Geobacillus: a potential enzyme for the biosynthesis of complex carbohydrates. Appl Microbiol Biot. 2005;68:757-67.

12. Kato N, Suyama S, Shirokane M, Kato M, Kobayashi T, Tsukagoshi N. Novel aglucosidase from Asperillus nidurans with strong transglycosylation activity. Appl Environ Microbiol. 2002;68:1250-6.

13. Kobayashi I, Tokuda M, Hashimoto H, Konda T, Nakano H, Kitahata S. Purification and characterization of a new type of a-glucosidase from
Paecilomyces lilacinus that has transglycosylation activity to produce $a-1,3$ and a-1,2 linked oligosaccharides. Biosci Biotechnol Biochem. 2003;67:29-35.

14. Zhou C, Xue YF, Zhang YL, Zeng Y, Ma YH. Recombinant expression and characterization of Thermoanaerobacter tengcongensis thermostable aglucosidase with regioselectivity for high-yield isomaltooligosaccharides synthesis. J Microbiol Biotechn. 2009;19:1547-56.

15. Crout DHC, Critchley P, Muller D, Scigelova M, Singh S, Vic G. Application of glycosylases in the synthesis of complex carbohydrates. 1999; pp.15-23. In Gilbert HJ, Davies GJ, Henrissat B, Svensson B. (eds.). Recent Advances in Carbohydrate Bioengineering. The Royal Society of Chemistry, Cambridge, UK.

16. Kurimoto $M$, Nishimoto $T$, Nakada $T$, Chaen $H$, Fukuda S, Tsujisaka $Y$. Synthesis by an a-glucosidase of glycosyl- trehaloses with an isomaltosyl residue. Biosci Biotechnol Biochem. 1997:61:699-703.

17. Mala S, Dvorakova H, Hrabal R, Kralova B. Towards regioselective synthesis of oligosaccharides by use of alpha-glucosidases with different substrate specificity. Carbohyd Res. 1999;322:209-18.

18. Takenaka F, Uchiyama H. Synthesis of alpha-D-glucosylglycerol by alphaglucosidase and some of its characteristics. Biosci Biotech Biochem. 2000;64:1821-6.

19. Cihan AC, Benli M, Cokmus C. Purification and characterization of intracellular and extracellular a-glucosidases from Geobacillus toebii strain E134. Cell Biochem Funct. 2012;30(1):69-81.

20. Nashiru O, Koh S, Lee SY, Lee DS. Novel a-glucosidase from extreme thermophile Thermus caldophilus GK24. J Biochem Mol Biol. 2001;34:347-54.

21. Park I, Lee $\mathrm{H}$, Cha J. Glycoconjugates synthesized via transglycosylation by a thermostable a-glucosidase from Thermoplasma acidophilum and its glycosynthase mutant. Biotechnol Lett. 2014;36(4):789-96.

22. Tsujimoto Y, Tanaka H, Takemura R, Yokogawa T, Shimonaka A, Matsui H, et al. Molecular determinants of substrate recognition in thermostable alpha-glucosidases belonging to glycoside hydrolase family 13. J Biochem. 2007;142(1):87-93.

23. Susana A, Milton SC, Nuno E. Molecular and Physiological Role of the Trehalose-Hydrolyzing a-glucosidase from Thermus thermophilus HB27. J Bacteriol. 2008;190:2298-305.

24. Yang S, Zhang S. Purification and characterization of alpha-glucosidase from an extreme thermophile, Thermus thermophilus HB8. Wei Sheng Wu Xue Bao. 1992;32:23-9.

25. Muslin $\mathrm{EH}$, Clark SE, Henson CA. The effect of proline insertions on the thermostability of a barley a-glucosidase. Protein Eng. 2002;15:29-33.

26. Zhou C, Xue YF, Ma YH. Enhancing the thermostability of alpha-glucosidase from Thermoanaerobacter tengcongensis MB4 by single proline substitution. J Biosci Bioeng. 2010;110:12-7.

27. Pantazaki AA, Pritsa AA, Kyriadidis DA. Biotechnologically relevant enzymes from Thermus thermophilus. Appl Microbiol Biot. 2002;58:1-12.

28. Kelly CT, Fogarty W. Microbial a-glucosidase. Process Biochem. 1983:18:6-12.

29. Chiba S. Molecular Mechanism in a-Glucosidase and Glucoamylase. Biosci Biotech Biochem. 1997:61:1233-9.

30. Miyazaki K. MEGAWHOP cloning: a method of creating random mutagenesis libraries via megaprimer PCR of whole plasmids. Methods Enzymol. 2011;498:399-406.

31. Glieder A, Farinas ET, Arnold FH. Laboratory evolution of a soluble, selfsufficient, highly active alkane hydroxylase. Nat Biotechnol. 2002;20:1135-9.

32. Wong TS, Arnold FH, Schwaneberg U. Laboratory evolution of cytochrome p450 BM-3 monooxygenase for organic cosolvents. Biotechnol Bioeng. 2004;85:351-8.

33. Noguchi A, Yano M, Ohshima Y, Hemmi H, Inohara-Ochiai M, Okada M et al. Deciphering the molecular basis of the broad substrate specificity of alpha-glucosidase from Bacillus sp. SAM1606. J Biochem. 2003;134:543-50.

34. Tanner JJ, Lei B, Tu SC, Krause KL. Flavin reductase P: structure of a dimeric enzyme that reduces flavin. Biochemistry. 1996:35:13531-9.

35. Chakravarty S, Varadarajan R. Elucidation of determinants of protein stability through genome sequence analysis. FEBS Lett. 2000:470:65-9.

36. Britton KL, Baker PJ, Borges KM, Engel PC, Pasquo A, Rice DW, et al. Insights into thermalstability from a comparison of the glutamate dehydrogenases from Pyrococcus furiosus and Thermococcus litoralis. Eur J Biochem 1995;229:688-95.

37. Matsumura M, Becktel WJ, Matthews BW. Hydrophobic stabilization in T4 lysozyme determined directly by multiple substitution of lle 3. Nature. 1988:334:406-10

38. Pace CN. Contribution of the hydrophobic effect to globular protein stability. J Mol Biol. 1992;226:29-35. 
39. Bradford MM. A rapid and sensitive method for the quantitation of microgram quantities of protein utilizing the principle of protein-dye binding. Anal Biochem. 1976;72:248-54.

40. Kanda T, Yatomi H, Makishima S, Amano Y, Nisizawa K. Substrate Specificities of Exo- and Endo-Type Cellulases in the Hydrolysis of $\beta-(1 \rightarrow 3)$ and $\beta$-(1 $\rightarrow$ 4)-Mixed D-Glucans. J Biochem. 1989;150:127-32.

41. Studier FW. Protein production by auto-induction in high density shaking cultures. Protein Expr Purif. 2005;41(1):207-34.

42. Eijsink VG, Vriend G, Van der Vinne B, Hazes B, Van de Burg B, Venema G. Effects of changing the interaction between subdomains on the thermostability of Bacillus neutral proteases. Proteins. 1992;14:224-36.

\section{Submit your next manuscript to BioMed Central} and take full advantage of:

- Convenient online submission

- Thorough peer review

- No space constraints or color figure charges

- Immediate publication on acceptance

- Inclusion in PubMed, CAS, Scopus and Google Scholar

- Research which is freely available for redistribution 